\title{
BMJ The high cost of diarrhoeal illness for OPen urban slum households-a cost-recovery approach: a cohort study
}

\author{
Ronak B Patel, ${ }^{1,2}$ Hanni Stoklosa, ${ }^{1}$ Shrutika Shitole, ${ }^{3}$ Tejal Shitole, ${ }^{3}$ Kiran Sawant, ${ }^{3}$ \\ Mahesh Nanarkar, ${ }^{3}$ Ramnath Subbaraman, ${ }^{3}$ Alison Ridpath, ${ }^{2}$ Anita Patil-Deshmuk ${ }^{3}$
}

To cite: Patel RB, Stoklosa $\mathrm{H}$, Shitole S, et al. The high cost of diarrhoeal illness for urban slum households-a costrecovery approach: a cohort study. BMJ Open 2013;3: e002251. doi:10.1136/ bmjopen-2012-002251

- Prepublication history for this paper are available online. To view these files please visit the journal online (http://dx.doi.org/10.1136/ bmjopen-2012-002251)

Received 22 October 2012 Revised 11 February 2013 Accepted 7 March 2013

This final article is available for use under the terms of the Creative Commons Attribution Non-Commercial 2.0 Licence; see http://bmjopen.bmj.com

${ }^{1}$ Departments of Emergency Medicine, Brigham and Women's Hospital and Massachusetts General Hospital, Boston, Massachusetts, USA ${ }^{2}$ Harvard Humanitarian Initiative, Cambridge, Massachusetts, USA ${ }^{3}$ Partners for Urban Knowledge Action and Research, Mumbai, Maharashtra, India

Correspondence to Dr Ronak B Patel; rbpatel1@partners.org

\section{ABSTRACT}

Objectives: Rapid urbanisation has often meant that public infrastructure has not kept pace with growth leading to urban slums with poor access to water and sanitation and high rates of diarrhoea with greater household costs due to illness. This study sought to determine the monetary cost of diarrhoea to urban slum households in Kaula Bandar slum in Mumbai, India. The study also tested the hypotheses that the cost of water and sanitation infrastructure may be surpassed by the cumulative costs of diarrhoea for households in an urban slum community.

Design: A cohort study using a baseline survey of a random sample followed by a systematic longitudinal household survey. The baseline survey was administered to a random sample of households. The systematic longitudinal survey was administered to every available household in the community with a case of diarrhoea for a period of 5 weeks.

Participants: Every household in Kaula Bandar was approached for the longitudinal survey and all available and consenting adults were included.

Results: The direct cost of medical care for having at least one person in the household with diarrhoea was 205 rupees. Other direct costs brought total expenses to 291 rupees. Adding an average loss of 55 rupees per household from lost wages and monetising lost productivity from homemakers gave a total loss of 409 rupees per household. During the 5-week study period, this community lost an estimated 163600 rupees or 3635 US dollars due to diarrhoeal illness.

Conclusions: The lack of basic water and sanitation infrastructure is expensive for urban slum households in this community. Financing approaches that transfer that cost to infrastructure development to prevent illness may be feasible. These findings along with the myriad of unmeasured benefits of preventing diarrhoeal illness add to pressing arguments for investment in basic water and sanitation infrastructure.

\section{INTRODUCTION}

Globally, urban slums are characterised by dense populations with poor access to sanitation and clean water due to non-existent or poorly developed basic infrastructure. ${ }^{1-4}$ In

\section{ARTICLE SUMMARY}

Article focus

- To determine how costly diarrhoeal illness is for poor urban slum households.

- To test the hypothesis that the cumulative cost that an urban slum community incurs due to diarrhoea could, over a period of time, help cover the cost of water and sanitation infrastructure.

Key messages

- Urban poor slum households spend a significant amount of money and proportion of their income on costs related to diarrhoea.

- The cumulative costs that diarrhoea causes for poor urban slum households is significant and can, over a period of time, help finance the cost of water and sanitation infrastructure.

- Innovative financing schemes and investments should be made for urban slum water and sanitation infrastructure development to prevent illness and its role in driving poverty.

Strengths and limitations of this study

- A major strength of this study was its use of systematic longitudinal weekly household level data of income and expenses for the entire slum community as it relates to a common illness.

- A major limitation was the diversity of the community and thus the resulting variability in cost estimates and wide SD.

- A further limitation was the imprecision of cost estimates from recall rather than an exact budget or financial diary.

Mumbai, India, $62 \%$ of the city's population live in such slums, but they are concentrated on approximately $9 \%$ of the city's land. ${ }^{5}$ While the proportion of the urban slum population in Mumbai without access to basic water and sanitation is difficult to measure given the lack of clear definitions and differences between registered and unregistered slums, it is reasonably understood that most lack access to these basic services. 
Urban slum dwellers in general have difficulty in accessing sufficient quantities of quality water for many reasons, including lack of infrastructure, poor reliability, as well as cost. In Mumbai slums, research has shown that even in registered slums, where the government has provided some water access, the supply is intermittent, lasting at most $4 \mathrm{~h}$ a day, for example, between 6:00 and 10:00 in the morning. ${ }^{6}$

Kaula Bandar (KB), the study site, is an unregistered urban slum with a population of approximately 10000 12000 people all wedged onto a single wharf. KB is located on land that officially belongs to the Mumbai Port Trust, bringing it technically under the authority of the federal government. Given this peculiar legal status, although it resides in the city of Mumbai, this slum has very limited access to civic services normally provided by the city government, the Municipal Corporation of Greater Mumbai. Consequently, nearly all children and $14 \%$ of adult residents defecate in the surrounding ocean, while $59 \%$ of the adults use a pay toilet and $40 \%$ use public toilets that are barely functional (Partners for Urban Knowledge, Action, and Research. Kaula Bandar baseline needs assessment, PUKAR: Mumbai, unpublished). Residents of this community also report that there are many days at a time, especially during the summer season, when there is no water flow through their haphazard water network due to water pressure issues, or loss of the motors that are taken away by the authorities every 5-6 months and must be repurchased by the water sellers. This network is a mixture of water bought through private sellers and illegal connections into the city water supply. The intermittent water access not only leads to diminished supply shared among too many users but also to increased water contamination. ${ }^{8}$

The system of water distribution in $\mathrm{KB}$ is complex and much more unreliable than the formal distribution system provided by the city government. Middle class residents of Mumbai have city water that is piped directly into their homes, and many registered slum residents receive water through city-provided common community water taps. In contrast, KB, an unregistered slum, has no formal water supply. A few years ago, some residents of $\mathrm{KB}$ discovered an old underground fire department pipe, and started accessing it with a series of connections linked to pumps. These KB residents now sell and distribute the water to local residents through an elaborate system of hoses. This complex system is problematic, as its extensive web requires many interval pumps to maintain water flow and because the exposed, poorly maintained hosing traverses a precarious route through seawater that includes refuse and faeces.

Residents of $\mathrm{KB}$ report that there are days at a time when water is not available through this complex hose network system, leaving the community residents without a reliable source of water. This happens quite frequently during the summertime. In these dire circumstances, residents obtain water from the neighbouring communities up to $5 \mathrm{~km}$ away; buy water sold from expensive private water tanker trucks; or simply go without water.

This water delivery system is not only inferior because of quality and quantity but also very costly. For water piped into their homes, middle class Mumbai residents are charged merely 3.5 rupees/1000 litres of water. In contrast, KB residents pay anywhere from 146 to 464 rupees/1000 litres of water. ${ }^{8}$ The ultimate cost to $\mathrm{KB}$ residents is significant because they are indirectly charged for not only for the distributors' salaries but also the pump fuel costs, water hose replacement costs, pump replacement costs and large bribes to the local police to avoid seizures of the pump motors.

Clean water, proper sanitation infrastructure and hygiene practices comprise the three biggest factors in ensuring freedom from water-born illness. The disparity in access felt by urban slums translates into human lives lost, particularly in children under the age of five, who are especially vulnerable to the effects of waterborne illness, including diarrhoea leading to increased morbidity and mortality. ${ }^{9-15}$ Annual cases of diarrhoea among urban slum dwellers in Mumbai is estimated to be as high as $614 / 1000$ people, with $30-60 \%$ of households and $12-30 \%$ individuals affected by water-related diseases a year. ${ }^{6}$ In KB, $91.2 \%$ of $\mathrm{KB}$ residents stated that the lack of water affected the health of their family members (Partners for Urban Knowledge, Action, and Research. Kaula Bandar baseline needs assessment, PUKAR: Mumbai, unpublished).

Poor access to sufficient quantities and quality of water along with inadequate waste management leads to waterborne illness. ${ }^{9} 16$ This burden of disease can carry real monetary costs in the form of lost days of employment, healthcare costs, cost of increased water and toilet use. The total costs of inadequate water access may be even greater. As decreased access to safe drinking water and adequate sanitation contribute to waterborne illness, malnutrition and, in turn, stunting, this results in poorer cognitive development and performance in school. ${ }^{17} 19$ These setbacks may result in delayed entry into the labour market and lesser earnings. Although not based on empirical data, the WHO estimates that globally, the lack of adequate water and sanitation leads to health costs of at least US $\$ 340$ million for households and US $\$ 7$ billion for national health systems. ${ }^{20}$ The World Bank estimates that India specifically loses $6.4 \%$ of its gross domestic product (GDP) every year to water and sanitation-related diseases. ${ }^{21}$

Locally, a large community survey of KB showed that $39.3 \%$ of individuals felt that the community's lack of water negatively affected their ability to go to work, $9.2 \%$ to go to school, $4 \%$ to study, $1.4 \%$ to start a new business and $1.5 \%$ to increase productivity in current business (Partners for Urban Knowledge, Action, and Research. Kaula Bandar baseline needs assessment, PUKAR: Mumbai, unpublished). However, it is unknown if these effects are directly tied to the negative-health implication of lacking water or other problems associated with poor access. 
Also, there are no data translating this into the actual monetary costs of the diarrhoeal illness in KB.

A study of 959 households in KB showed that a large proportion of KB occupants $(45.7 \%)$ had monthly direct health expenditures (doctors, medicines and hospital fees) greater than 500 rupees, which for families living on meagre income fall under the category of catastrophic expenditure (Partners for Urban Knowledge, Action, and Research. Kaula Bandar baseline needs assessment, PUKAR: Mumbai, unpublished).$^{22}$

Given high household expenditure on illness, preventative-health interventions, implemented correctly, may not only be cost-effective but also more affordable for many urban poor. This study investigates the cost of diarrhoeal illness in the community to determine the household monetary cost of having a member with diarrhoea. These costs are calculated as direct and monetised indirect costs to determine the amount that diarrhoeal illness contributes to household expenditure and lost productivity. These costs are then projected for the community at large as figures to compare against the cost of potential interventions to improve water and sanitation infrastructure. While the presence of this infrastructure would not eliminate all cases of diarrhoea or all modes of transmission, it would significantly reduce many common sources and the availability of clean water would allow for better hygiene to protect against some sources that are not eliminated.

\section{METHODS}

\section{Sampling and data collection}

For data collection, two surveys were administered. The surveys were designed through community focus group discussions, the authors' experience with the community from previous work as well as extensive pretesting various versions of the survey and individual questions from January to May 2011. Official data collection for the study occurred in July 2011, during the monsoon season. This study was undertaken in collaboration with the local research organisation, Partners for Urban Knowledge Action and Research (PUKAR).

Community-based 'barefoot researchers' trained in social science research at PUKAR who had previous experience administering surveys in the community verbally administered the surveys in the local language for this study. Using data-collectors from the community has many advantages and became essential to a study of this type. It most importantly allowed the research team to gain social capital with the community and improve participation. It also allowed fine-tuning of survey questions given the insights that they provide about their own water, sanitation and health practices. These communitybased researchers assisted with pilot testing many questions to ensure that the questions captured the information they were intended to capture. Multiple rounds of training avoided initial disadvantages such as inconsistent survey administration with rephrasing questions, not probing certain responses, recording assumptions instead of responses and leading questions. Additionally, a member of the study team accompanied each 'barefoot researcher' in the field.

The study only had one exclusion and one inclusion criteria. Households with a head of household less than 18 years of age were excluded due to Institutional Review Board (IRB) approval for adults only and respondents that could reasonably answer questions about household finances were included. Most often, the respondent was a woman. The term household in this study refers to all members living in a dwelling.

\section{Baseline survey}

The baseline survey included questions about water access, hygiene and sanitation and average household expenditure on various goods in the KB community. These households did not necessarily have a diarrhoeal case. The entire community of $\mathrm{KB}$ was mapped and each household coded with an individual designation developing a comprehensive registry of households. A random number generator was then used to collect data on a sample of households from this registry resulting in 203 households in the baseline survey. This baseline survey was meant to simply get an understanding of general household income and expenditure as well as health practices to better formulate the longitudinal survey. Some questions were repeated after reformulation in the longitudinal survey based on the baseline survey results.

\section{Longitudinal survey}

The longitudinal survey was designed to understand the direct and indirect costs associated with diarrhoeal cases in KB. Diarrhoea was defined according to the WHO definition and the study staff and the survey respondents were taught this definition when collecting data. Direct costs included all healthcare-associated costs including ORS, medications, transport to reach a provider and provider fees as well. Avoidance costs included expenses from the extra water purchased, extra kerosene purchased for boiling and extra money spent on accessing a toilet facility. Indirect costs included wages lost by earners with diarrhoea or those caring for persons with diarrhoea and households chores not completed.

During the month of July 2011, the community barefoot researchers visited all 2922 households in KB weekly for a total of 5 weeks. This period of 5 weeks was used in order to collect a reasonable sample of households representing almost $10 \%$ of the calendar year and stay within the constraints of the resources available. If a head of household over 18 years of age was available, and the household had a case of diarrhoea for which the disease course had been completed during the past week, they were invited to participate in the study. Survey data were only collected for households with a completed case of diarrhoea so that the data would reflect full costs for the entire episode of illness. Active, 
ongoing cases were recorded every week so that researchers could specifically follow-up with those households the next week (once the diarrhoeal illness was completed) with the full survey questionnaire. Four hundred households with a case of diarrhoea contributed to the weekly survey data during the 5-week study period in the month of July 2011.

Given that the majority of women in this community are not wage earners, we attempted to capture the productivity that homemakers provide to the household and the amount of that productivity that is lost by diarrhoeal illness as an opportunity cost. Using a replacement value methodology with a hypothetical maid and focusing on nine major daily tasks conducted by women with a an urban replacement cost of US $\$ 6.1$ or 274 rupees per task per month during the time of this study, we calculated the total indirect costs to households from a women's lost productivity. ${ }^{23}$ The 274 rupees per month per daily task convert into an average cost of 9 rupees per individual task. To ensure that only chores that were foregone are included, women were asked to report if these chores were actually not carried out or they were completed with free help from another person or simply delayed in the day or week. The opportunity cost was then the product of the forgone number chores and the cost to hire a person to complete that chore using the hypothetical maid and urban replacement cost above.

\section{Data analysis}

The data were recorded by hand on paper and transferred to an EpiData database by the data manager as soon as the results were provided to PUKAR. Statistical analysis was performed using STATA MP V.10, College Station, Texas, USA. Data on cost measures from the longitudinal survey were analysed after eliminating the top $5 \%$ and bottom $5 \%$ of values among the population to exclude the effect of outliers. Although some catastrophic events may have been excluded by this process, we found that the mean and median values did not differ greatly, but some variability at the two ends was eliminated by eliminating the outliers.

\section{Data storage}

Only researchers associated with the PUKAR team had access to the survey information. All data regarding specific homes from which data were collected were stored at the PUKAR office on a password protected hard disk. All results of the study were analysed and are published in an anonymised fashion.

\section{Ethical considerations}

Heads of households provided informed consent. The households who participated in the study as well as other residents received education on recognising signs and symptoms of diarrhoea through pictorial posters. The female members of the household who usually bore the brunt of caretaking for persons with diarrhoea in the home were taught about the initial treatments such as ORS and were educated on when their family members should been seen by a doctor in case of deterioration in condition. This study received IRB an approval from the PUKAR Institutional Ethics Committee as well as the Partners Human Research Committee associated with Harvard Medical School-based researchers in Boston, Massachusetts, USA.

\section{RESULTS}

A total of 203 households, $6.9 \%$ of the 2922 households in the community, provided data for the baseline survey. Systematically visiting every household for the weekly longitudinal survey resulted in 400 households providing data as these were the homes with completed diarrhoea cases during the study period. There was some repetition with 49 homes reporting cases twice within the study period and 9 households reporting 3 weeks with a case of diarrhoea. The sample of 400 household events represents $13.7 \%$ of KB homes. The age distribution of cases showed that all children under 5 years of age accounted for $35 \%$ of cases, while those under 1-year accounted for $11 \%$. Those aged 5-18 years accounted for another $25 \%$ of cases and adults made up the reaming $40 \%$.

The percentage of homes occupied and thus available for survey every given week ranged from $67 \%$ to $73.2 \%$, showing that at least $2 / 3$ of the community was available for survey each week. Of these available households, there was a negligible non-response rate ranging from $0.5 \%$ to $1.2 \%$, thus having minimal effect on the study results.

Baseline demographic information from the baseline survey, displayed in table 1 , shows that the population of this slum is predominantly men and young with 1.2 men for every women. Part of this ratio is related to the presence of many single migrant labourers in the community. Additionally, only about $10 \%$ of the population was over the age of 40 . Children under 5 years of age, representing the most vulnerable population to diarrhoeal illness, make up slightly over $15 \%$ of the population.

General household financial data from the baseline survey, displayed in table 1 , show basic income and consumption information. Each household had on average

\begin{tabular}{ll}
$\begin{array}{l}\text { Table } 1 \text { General household information from baseline } \\
\text { survey }\end{array}$ \\
\hline Male & $55 \%$ \\
Female & $45 \%$ \\
Age (median) & 20 years \\
Children under 5 & $15 \%$ \\
Income (median) & Rs 5000-5999 \\
Basic monthly expenses (Rent, food, & Rs 4609 \\
electricity, kerosene) & \\
Water expenses (median) & Rs 300-449 \\
Possess ration card & $68.5 \%$ \\
Save money each month & $26.6 \%$ \\
\hline
\end{tabular}


1.7 wage earners per household with $32 \%$ of the population earning a wage. Of the roughly quarter of households that are able to save each month, the median savings is 1500 rupees.

After discussions with households and advice from persons within the community, household costs were broken down into several major categories: rent, food, water, electricity and kerosene. While these categories do not comprehensively capture the total costs of each household, they represent the major recurring basic costs that each household incurs for their general welfare. The average monthly expenditure on these basics excluding water was 4609 rupees with an additional median of 300-450 rupees spent on water alone.

Diarrhoea in this community was reported on a weekly basis during the 5-week course of the study as active cases and cases that had just completed that week. The general weekly prevalence of diarrhoea per household ranged from $5.9 \%$ to $9.2 \%$ during this monsoon season.

The costs of diarrhoea to these households was measured and reported here in terms of direct medical costs, avoidance costs and lost wages from income and costs from homemakers' productivity loss, table 2.

Basic direct costs included all healthcare-associated costs including ORS, medications, transport to a provider and provider fees. Although transport to a provider is commonly considered a non-medical cost, we combine it here because access to healthcare is a major issue for the urban poor and transport to a healthcare provider is an important part of the cost to access healthcare. The majority of people, $62 \%$, accessed a private provider with a local doctor and $15 \%$ went to a pharmacy for care.

Avoidance costs were tabulated separately as increased costs due to the extra water purchased, extrakerosene purchased for boiling and extramoney spent on accessing a toilet facility.

Lost wages represented the wages lost by income-earners with diarrhoea or those caring for persons with diarrhoea. In the community, $16.5 \%$ of households lost some wages from income-earning employment due to diarrhoea. While this value varied,

\begin{tabular}{lll}
$\begin{array}{l}\text { Table } 2 \\
\text { rupees (Rs) } \pm \text { SD }\end{array}$ & & \\
\hline Metric & Cost \pm SD & $\mathbf{n}$ \\
\hline $\begin{array}{l}\text { Basic direct costs } \\
\text { (ORS, provider fee, transport, }\end{array}$ & $205 \pm 190$ & 310 \\
$\begin{array}{l}\text { medication costs) } \\
\text { Avoidance costs } \\
\text { (extra water, kerosene and toilet } \\
\text { fees) }\end{array}$ & $86 \pm 81$ & 201 \\
$\begin{array}{l}\text { Lost wages from income } \\
\text { Homemaker's productivity loss } \\
\text { (foregone chores monetised) }\end{array}$ & $55 \pm 160$ & 384 \\
Total & 63 & 400 \\
\hline
\end{tabular}

these households lost a median of 500 rupees of income for the episode from missed employment. Spreading this loss over all the households and calculating the loss overall yields a mean loss of 55 rupees per household.

On an average, women in the household with a case of diarrhoea were unable to complete an average of seven tasks that week due to a case of diarrhoea in the household. The cost from the monetised value of foregone chores based on the replacement cost method of hiring a maid is reported.

Given the values above, the cost of illness to each household from a case of diarrhoea can be reported in several ways. The basic direct cost is 205 rupees. Avoidance costs of 86 rupees give a total of 291 rupees. Adding the mean loss of 55 rupees per household from lost income brings the total to 346 rupees per household and adding the monetised productivity lost from homemakers of 63 rupees brings the total to 409 rupees.

Simply using the 400 cases of diarrhoea from this community found during this 5-week study period from the houses available for survey alone yields a total basic direct cost of 82000 rupees or US $\$ 1822$ using the exchange rate present at time of study. The complete total cost of 409 rupees per household yields a loss of 163600 rupees or US\$3635 to the community over the 5 -week study period.

These results rely on household incidence of diarrhoea regardless of age and no reliable measure of diarrhoeal incidence at the household unit exists for a similar population to estimate the yearly costs for this population. Using a conservative assumption, however, that each household will suffer at least one case of diarrhoea per year, the basic direct cost of diarrhoeal illness in this community of 2922 households yields a yearly total community-wide cost of 1195098 rupees (US \$26 557).

\section{DISCUSSION}

This study provides direct household level data on the cost of diarrhoeal illness to urban slum residents in this community. Longitudinally interviewing every available household consecutively for five straight weeks provides rigorous insight into the weekly income and expenditure habits of these residents as they relate to diarrhoeal illness. Given the thorough nature of the data collection, this study provides strong evidence that diarrhoeal illness incurs significant costs to urban slum households. More importantly, this study provides expenditure and illness costs that can be compared against the cost of infrastructure upgrades for water and sanitation systems. The savings from lower costs of water and sanitation from improved infrastructure can be put towards paying for that infrastructure and over time completely finance it. This study provides evidence that the savings from a reduction in some cases of diarrhoea from such infrastructure may also help finance it by these costs from the back end of paying for illness to the front end could 
pay for themselves. With every illness episode, each household loses an average of 205 rupees in direct basic costs and 346 rupees in total avoidable total costs. Reducing these illness episodes can provide a significant savings benefit that can be used to finance the infrastructure upgrades.

This study adds further evidence to break the myth that urban slum populations do not have the financial capacity to pay for improved infrastructure. Just as many reports have shown that these households in fact pay a high price for basic goods and services from both official and unofficial sources, this study shows that households also pay a high price for illness given that it represents $7-8 \%$ of their monthly income and almost $30 \%$ of their weekly income. While not a novel concept, this study provides concrete numbers on the cost that illness inflicts on the urban poor and shows how these households, as a community, have the financial capacity to finance infrastructure they need simply from the savings in prevented illness. Although this is not an argument for such a model, it adds further evidence that upfront investment in basic infrastructure can be financially supported by a resulting reduction in illness. The savings realised by these households from an infrastructure investment could then be put towards other basic needs in nutrition, education and health.

Despite the rigorous methodology, the study suffers from a few limitations. While the values for cost are rigorously collected from every available household, they are the best estimate from the surveyed adult. The data were not gathered from detailed budgets, financial diaries or accounts held by these households but rather by recall. The diversity of the population within this community added to the variability and high SDs seen in the data. This reflects the true nature of many urban slums that have a high variability in socioeconomic status. Another limitation is that while improved water and sanitation infrastructure can have a significant impact on reducing illness, proper hygiene plays another major role. Infrastructure upgrades alone will not eliminate the burden of diarrhoeal illness, and thus all of the cost from diarrhoeal illness cannot be attributed to the lack of such infrastructure. Accordingly, the total savings realised by such an infrastructure upgrade would be less. This community, however, has a high reported rate of hand hygiene with $86 \%$ of households washing their hands before eating and $90 \%$ washing their hands after defaecating. Additionally, $87 \%$ of the population reported using soap either before eating, after defaecating or both. Thus, most of the costs estimated from this study are all likely costs that can be saved through infrastructure upgrades to compliment this hand hygiene. While estimates on the exact magnitude of benefit from water and sanitation infrastructure vary, a recent meta-analysis of interventions in developing countries concluded that improved water supply could reduce diarrhoea by about $25 \% .^{24}$ A sanitation intervention would further provide reductions. This meta-analysis concluded that a combination of multiple interventions including improved water supply and quality, improved sanitation and hygiene could reduce diarrhoeal disease by $33 \% .{ }^{24}$ Given that hand hygiene was high in this community, the estimated reduction in diarrhoea by a combined water and sanitation intervention would likely be slightly less.

Only $56.5 \%$ persons with diarrhoea in this study used ORS. A higher rate of early ORS use might have averted more costly healthcare expenses such as the need to access a healthcare provider thereby reducing the overall cost of the illness measured in this study. This limitation is hypothetical, however, because it is unclear if any of the cases that did not use ORS would have needed it or if they were associated with seeking more expensive care elsewhere to increase the household costs. Finally, the care-seeking behaviour for diarrhoea itself may be viewed as a limitation as most cases do not require care outside the home and better education might prevent these costs from being incurred by families. Whatever the impact of improved care-seeking behaviour on the cost estimates, however, this study estimates the current real cost households incur due to diarrhoeal illness which can be saved and put towards public-health interventions aimed at reducing this burden, including infrastructure upgrades.

Many of the estimates of cost here may actually be underestimates. This particular community did not have many female income earners in the household. Many urban slum communities have a higher rate of women that are employed in the informal sector, but still live in communities such as this one with poor water and sanitation infrastructure. If that informal employment were outside the home, they would forgo income from having to stay home with an ill child. Additionally, the time spent on activities such as travelling to the toilet and fetching water were not adequately collected in this study, adding further indirect costs to diarrhoeal illness not included in this estimate. We could not collect enough data on savings and debt among these households to make a correlation between illness and debt in this community, but previous studies have shown that illness is an indebting event for many urban poor. A larger and more comprehensive study may have been able to capture that value showing a further cost in the lost savings and higher payments made on loans for such borrowing. Finally, if malnutrition, stunting, poor school performance, delayed and incomplete education and poor cognitive development could be included along with the resulting decreased economic opportunities as well as mortality on overall GDP, there would be an even greater cost attributable to diarrhoeal illness in urban slum communities similar to KB.

Given the study findings, policy-makers and those with programmes aimed at aiding urban slum populations should understand the potential savings from preventing diarrhoeal illness with improved water and sanitation infrastructure. A current intervention to provide piped 
water to $\mathrm{KB}$ has an estimated cost of 2.5 million rupees. While this intervention will not provide each household with a personal tap, community taps that increase water availability and ensure quality have the potential to reduce diarrhoea morbidity. The potential reduction in diarrhoea from such an intervention may aid the community to help finance this intervention over a period of time from the lower diarrhoeal cost savings by adding to the savings from cheaper water.

This financial argument for water and sanitation infrastructure complements the right to water and sanitation that all persons have. This right to water and sanitation is a part of a larger legal and human rights framework. On 28 July 2010, the UN General Assembly adopted resolution 64/292 acknowledging that clean water and sanitation are essential to achieving all human rights. ${ }^{25}$ International organisations and all states are directed to provide adequate and affordable access to clean water and sanitation for all persons. This research on the community and household financial implications of poor water and sanitation adds to this human rights approach with a further pragmatic and operational validation of the need for clean water and sanitation provision to even the most difficult to reach populations.

This study provides data on the cost of diarrhoeal illness to urban slum households and allows an analysis of cost-recovery for various interventions. This study begins to explore how the expected health benefits may help finance such interventions in urban slum communities. Whether government financed through taxes or privately through fees or microlending or even socially through savings cooperatives, financial vehicles to promote infrastructures upgrades may be financially viable methods of development. While this study argues for improved infrastructure, the potential cost savings from improved health and illness prevention may be used to finance various types of health promotion and public-health activities. These potential savings should be calculated and considered in cost-benefit analyses. Further research is needed on the best methods of preventing illness, improving care-seeking behaviour and healthcare quality among urban slum communities.

Contributors All authors met the guidelines for authorship with substantive input on study design, pilot testing instruments, data collection and analysis and final manuscript writing and editing. The major design of the study was developed by the first, second and last authors (RBP, HS and AP-D). Survey instrument development, pilot testing, editing and data collection was done by all and heavily by SS, TS, KS, MN and RS. Data analysis was performed primarily by RBP. Manuscript writing was done primarily by RBP and HS with editing from all of the other authors.

Funding Rockefeller Foundation provided financial support.

Competing interests None.

Ethics approval Partners Human Research Committee associated with Harvard Medical School.

Provenance and peer review Not commissioned; externally peer reviewed.

Data sharing statement Additional unpublished baseline and longitudinal survey raw data on some general income and minor expenses as well as some minimal information collected on care seeking behaviour can be made available by request to the corresponding author.

\section{REFERENCES}

1. Bartram J, Cairncross $S$. The growing issue of urban water supply, Supporting Text 3. PLoS Med 2010;7:1-2.

2. Galea S, Vlahov D. Urban health: evidence, challenges, and directions. Ann Rev Public Health 2005;26:341-65.

3. Harpham T. Urban health in developing countries: what do we know and where do we go? Health Place 2009;15:107-16.

4. Madhiwala N. Healthcare in urban slums in India. Natl Med $J$ India 2007;20:113-14.

5. Das PK. Slum map of Mumbai Part 1. Mumbai: Nivara Hakk Suraksha Samiti, 2011.

6. Kumar Karn S, Shikura S, Harada H. Living environment and health of urban poor: a study in Mumbai. Econ Political Wkly 2003;38:3575-7, +3579-3586.

7. Kumar Karn S, Harada H. Field survey on water supply, sanitation and associated health impacts in urban poor communities-a case from Mumbai City, India. Water Sci Technol 2002;46:269-75.

8. Subbaraman R, Shitole S, Sawant K, et al. "Failures in quality, quantity, and reliability of water provided through an informal distribution system in a slum in Mumbai, India" [Abstract OS40.6] Oral Presentation. 10th International Conference on Urban Health. November 2-4, 2011; Belo Horizonte, Brazil.

9. Bartram J, Cairncross S. Hygiene, sanitation, and water: forgotten foundations of health. PLoS Med 2010;7:1-9.

10. Bhatnagar S, Dosajh U. Diarrhoeal disease morbidity in children below 5 years in urban slums of Delhi. Indian J Med Res 1986;84:53-8.

11. Hussain A, Ali SM, Kvale G. Determinants of mortality among children in the urban slums of Dhaka city, Bangladesh. Trop Med Int Health 1999;4:758-64.

12. Choudhary SR, Jayaswal ON. Infant and early childhood mortality in urban slums under ICDS scheme-a prospective study. Indian Pediatr 1989;26:544-9.

13. Joe W, Mishra US, Navaneetham K. Socio-economic inequalities in child health: recent evidence from India. Glob Public Health 2010;5:493-508.

14. Gladstone BP, Das AR, Rehman AM, et al. Burden of illness in the first 3 years of life in an Indian slum. J Trop Pediatr 2010;56:221-6.

15. Gupta P, Murali MV, Seth A. Epidemiology of diarrhea in urban slums. Indian Pediatr 1998;35:147-51.

16. Esrey SA, Potash JB, Roberts L, et al. Effects of improved water supply and sanitation on ascariasis, diarrhoea, dracunculiasis, hookworm infection, schistosomiasis, and trachoma. Bull World Health Organ 1991;69:609-21.

17. Dillingham R, Guerrant RL. Childhood stunting: measuring and stemming the staggering costs of inadequate water and sanitation. Lancet 2004;363:94-5.

18. Niehaus M, Moore S, Patrick P, et al. Early childhood diarrhoea is associated with diminished cognitive function 4 to 7 years later in children in a northeast Brazilian shantytown. Am J Trop Hyg Med 2002;66:590-93.

19. Berkman D, Lescano A, Gilman R, et al. Effects of stunting, diarrhoeal disease, and parasitic infection during infancy on cognition in late childhood: a follow-up study. Lancet 2002;359:542-71.

20. Hutton G, Haller L. Evaluation of the costs and benefits of water and sanitation improvements at the global level. Geneva: World Health Organization, 2004.

21. The World Bank Water and Sanitation Program. The economic impacts of inadequate sanitation in India. New Delhi: World Bank, 2010. http://www.wsp.org/wsp/sites/wsp.org/files/publications/ wsp-esi-india.pdf (accessed 14 May 2011)

22. Xu K, Evans D, Kawabata K, et al. Household catastrophic health expenditure: a multicountry analysis. Lancet 2003;362:111-17.

23. Choudhary N, Tripathy A, George B. Women's economic contribution through their unpaid household work: the case of India. Evangelical Social Action Forum. Working Pap Ser 2009. http:// www.healthbridge.ca/India\%20summary\%20report\%20final.pdf (accessed 14 May 2011)

24. Fewtrell L, Colford JM Jr. HNP Discussion Paper: Water, Sanitation And Hygeine: Interventions And Diarrhoea-A Systematic Review and Meta-analysis. The World Bank, 2004. http://siteresources.worldbank. org/HEALTHNUTRITIONANDPOPULATION/Resources/2816271095698140167/Fewtrell\&ColfordJuly2004.pdf (accessed Jan 3, 2013)

25. United Nations. Resolution adopted by the General Assembly 64/ 292: The human right to water and sanitation. United Nations 2010. http://www.un.org/ga/search/view_doc.asp?symbol=A/RES/64/292 